\title{
MODIFIKASI KOPOLIMER KARET ALAM SIKLIS GRAFTING ASAM OLEAT MENGGUNAKAN INISIATOR BENZOIL PEROKSIDA DAN BAHAN PENGISI BENTONIT-CETIL TRIMETIL AMONIUM BROMIDA
}

\author{
MODIFICATION OF CYCLIC NATURAL RUBBER GRAFTING OLEIC ACID \\ COPOLYMER USING BENZOIL PEROXIDE INITIATOR AND THE FILLER OF \\ BENTONITE-CETYL TRIMETHYL AMMONIUM BROMIDE
}

\author{
Ahmad Hafizullah Ritonga*, Barita Aritonang, Liver Iman Putra Zai \\ Program Studi Kimia, Fakultas Sain, Teknologi, dan Informasi, Universitas Sari Mutiara Indonesia, \\ Jalan Kapten Muslim No. 79, Medan, Indonesia \\ *Corresponding Author : ahmad.hafizullah.r@gmail.com
}

Submit : 27 Oktober 2018 Accepted : 28 November 2018

\begin{abstract}
Research on the modification of Cyclic Natural Rubber (CNR) grafting Oleic Acid (OA) copolymer using initiator of Benzoyl Peroxide (BPO) and the filler of bentonite-Cetil Trimethyl Ammonium Bromide (CTAB) has been carried out, which aims to determine the method of modifying Cyclic Natural Rubber (CNR) and Oleic Acid (OA) so it can produce CNR-g-OA copolymer through grafting method with BPO initiator mixed together with bentonite-CTAB. This research was conducted in three stages. The first stage is the process of dissolving CNR using xylene. The second stage is the process of mixing CNR solution and OA with the composition (70:30) phr, followed by the addition of BPO initiator and bentonite-CTAB filler. The third stage is characterization using FTIR and Scanning Electron Microscopy (SEM). The results of the analysis using FT-IR showed an absorption at $1708,23 \mathrm{~cm}^{-1}$ which indicated the presence of $\mathrm{C}=\mathrm{O}$ bonds from oleic acid which had been grafted on CNR, and increased intensity after addition of bentonite-CTAB at 1568,96 $\mathrm{cm}^{-1} ; 1446,13 \mathrm{~cm}^{-1} ; 1255,66 \mathrm{~cm}^{-1}$; and $866,94 \mathrm{~cm}^{-1}$. Characterization results using SEM showed that the mixing of Bentonite-CTAB in KAS-g-OA was evenly distributed and quite homogeneous.
\end{abstract}

Keywords: Cyclic Natural Rubber, Oleic Acid, Bentonite, Cetyl Trimethyl Ammonium Bromide, Benzoyl Peroxide.

\section{PENDAHULUAN}

Modifikasi karet alam melalui proses kimia merupakan suatu upaya yang penting dilakukan agar dapat mengoptimalkan performa dari karet alam, sehingga dapat memperluas fungsi dan manfaatnya, serta dapat meningkatkan harga karet alam [1]. Modifikasi kimia dengan teknik pencangkokan (grafting) gugus telah banyak dilakukan untuk menghasilkan produk sesuai dengan spesifikasi yang diharapkan. Teknik grafting merupakan salah satu metode yang sederhana, mudah, dan telah banyak dilakukan [2]. Modifikasi kimia karet alam perlu dilakukan agar dapat memperbaiki kekurangan pada sifat karet alam tersebut, dan untuk mengubah karet alam tersebut menjadi suatu material baru dengan sifat-sifat yang berbeda dengan aplikasi tertentu.

Karet alam dapat dimodifikasi secara kimia melalui reaksi siklisasi sehingga dapat menghasilkan suatu material baru seperti karet alam siklis (Cyclic Natural Rubber). Karet alam siklis ini sendiri diperoleh melalui preparasi karet alam dengan asam kuat (seperti asam sulfat, asam p-toluenasulfonat) maupun katalis friedel-crafts (seperti $\mathrm{SnCl}_{4}, \mathrm{FeCl}_{3}, \mathrm{TiCl}_{4}$ ). Pada reaksi tersebut, karet kehilangan daya elastisitasnya dan berubah menjadi material yang keras dan rapuh [3]. Modifikasi karet alam dalam pelaksanaannya banyak menggunakan banyak reaksi kimia, seperti reaksi siklisasi, degradasi, halogenasi, hidrogenasi, epoksidasi, maleasi (maleinisation), maupun graft kopolimerisasi. Pengurangan jumlah ikatan rangkap dalam reaksi siklisasi bervariasi sekitar $40-90 \%$. Karet alam siklis pada saat ini banyak digunakan sebagai binder pada campuran antara cat dengan tinta cetak (printing ink) karena memiliki sifat khas, yaitu ringan, kaku, tahan abrasi (daya gesek) serta memiliki daya rekat yang cukup baik terhadap berbagai 
jenis material seperti kayu, kaca, logam, plastik, tekstil, kulit, dan kertas.

Karet alam siklis memang baik apabila digunakan sebagai bahan pengikat cat, akan tetapi karet alam siklis ini masih memiliki keterbatasan terutama dalam hal ketercampuran (compactibility) dengan bahan aditif dan resin lain yang umumnya sering digunakan di dalam industri cat maupun tinta. Selain itu juga sifat fisisnya yang kurang tahan terhadap sinar ultra violet, ozon, dan asam anorganik karena tingginya ikatan rangkap karbon $(>\mathrm{C}=\mathrm{C}<)$ pada rantai karbon siklis sehingga perlu dimodifikasi kembali membentuk material yang baru agar dapat meningkatkan kelarutan, ketercampuran dengan bahan aditif lainnya, dan mampu menurunkan ikatan rantai karbon tidak jenuh pada karet alam siklik sebelum digunakan sebagai bahan pengikat cat [4].

Penelitian terdahulu mengenai modifikasi karet alam siklis sebagai bahan pengikat cat diantaranya yaitu Siregar \& Syaputra [5] yang memodifikasi secara kimia karet alam siklis dengan maleat anhidrat melalui metode grafting menggunakan inisiator dikumil peroksida. Siregar, dkk [2] juga menggunakan inisiator lainnya yaitu benzoil peroksida untuk memodifikasi karet alam siklis dengan monomer metil metakrilat.

Dalam penelitian ini dilakukan modifikasi pada struktur karet alam siklis melalui metode grafting dengan menggunakan monomer asam oleat dan inisiator benzoil peroksida (BPO). Hal ini dianggap berhasil dilakukan karena asam oleat merupakan asam lemak tidak jenuh yang memiliki ikatan rangkap dan merupakan salah satu jenis material yang umum dipakai sebagai bahan aditif pada proses vulkanisasi karet alam dengan belerang. Komposisi asamnya juga hampir sama dengan maleat anhidrida (MA) yang dapat bereaksi dengan gugus hidroksil pada permukaan organoclay [6]. Hal tersebut juga diyakini dapat meningkatkan terjadinya proses interkalasi molekul asam oleat ke dalam ruang antar lapisan organoclay [7], ataupun jenis clay yang lain, seperti kaolinite [8], calcite [9], celtec [10], smectite [11], bentonit dengan CTAB [12].

Pemanfaatan bahan pengisi organoclay dianggap baik untuk terus dikembangkan, seperti pada penelitian Ritonga, dkk [13] yang menggunakan organobentonit yang dibuat dengan cara memodifikasi antara bentonit dengan $\mathrm{CTAB}$, yang kemudian terbentuk suatu produk berupa bentonit-CTAB yang difungsikan sebagai bahan pengisi untuk melakukan proses modifikasi pada karet alam siklis dengan monomer maleat anhidrat menggunakan inisiator benzoil peroksida melalui metode grafting.

Berdasarkan uraian tersebut, maka perlu dilakukan penelitian mengenai modifikasi kopolimer Karet Alam Siklis (KAS) grafting Asam Oleat (AO) dengan inisiator Benzoil Peroksida (BPO) dan bahan pengisi bentonit Cetil Trimetil Amonium Bromida (CTAB). Penelitian ini bertujuan untuk mengetahui cara dalam melakukan modifikasi pada karet alam siklis dan asam oleat dengan metode grafting menggunakan inisiator benzoil peroksida dan bahan pengisi Bentonit-CTAB, serta hasil karakterisasi dari produk KAS-g-AO/BentonitCTAB yang terbentuk.

\section{METODOLOGI PENELITIAN Alat dan Bahan}

Adapun peralatan yang digunakan dalam penelitian yaitu Gelas Beaker $500 \mathrm{ml}$, Gelas Ukur $10 \mathrm{~mL}$, Cawan Petri, Pipet Tetes, Thermometer $100{ }^{\circ} \mathrm{C}$, Statif dan Klem, Batang pengaduk, Spatula, Alu dan Lumpang, Neraca Analitis, Hot plate dan stirer, Alumunium Foil, Oven, Desikator, Scaning Elektron Microscopy, dan Spektrofotometri Infra Merah (FTIR). Untuk bahan kimia yang dipergunakan dalam penelitian terdiri dari Bentonit (Komersil), Cetil Trimetil Amonium Bromida (CTAB), Karet Alam Siklis (Resiprene 35), Asam Oleat, Benzoil Peroksida, dan Xylene.

\section{Preparasi Bentonit-CTAB dan Karet Alam Siklis}

Bentonit komersil dimodifikasi terlebih dahulu dengan Cetil Trimetil Amonimum Bromida (CTAB) sehingga diperoleh organobentonit yang selanjutnya disebut dengan Bentonit-CTAB dan dipersiapkan sebagai bahan pengisi. Pada tempat yang berbeda, Karet Alam Siklis (KAS) sebagai dihaluskan menggunakan alu dan lumpang sehingga diperoleh KAS dalam bentuk serbuk. Selanjutnya Dihidupkan alat pemanas hot plate, diletakan beaker glass $500 \mathrm{ml}$ diatasnya [13].

\section{Modifikasi Dengan Inisiator BPO \\ KAS-g-AO/Bentonit-CTAB}

Sebanyak $70 \mathrm{phr}$ serbuk KAS dimasukkan kedalam beaker glass yang terdapat magnetik stirer didalamnya, lalu ditambahkan dengan pelarut xylene secukupnya sambil diaduk menggunakan stirer dan dipanaskan pada suhu 50 ${ }^{\circ} \mathrm{C}$ hingga serbuk KAS larut semuanya. Setelah 
terbentuk larutan KAS, kemudian ditambahkan Asam Oleat sebanyak $30 \mathrm{phr}$, dan dibiarkan hingga AO tercampur secara merata dalam larutan KAS, selanjutnya ditambahkan dengan inisiator Benzoil Peroksida sebanyak $1 \mathrm{phr}$, diikuti dengan penambahan $3 \mathrm{phr}$ BentonitCTAB secara perlahan. Setelah semua komponen tercampur, lalu dibiarkan hingga campuran tersebut homogen selama \pm 1 (satu) jam dengan suhu pemanasan $50{ }^{\circ} \mathrm{C}$. Setelah campuran tersebut homogen, lalu dituang ke dalam cawan petri dan dikeringkan dalam oven selama 1 hari dengan suhu $60^{\circ} \mathrm{C}$. Campuran homogen tersebut dikeluarkan dari oven, dan disimpan selama 1 hari dalam desikator untuk menghilangkan aroma dari xylene. Hasil yang diperoleh kemudian dikarakterisasi dengan FTIR dan SEM [13].

\section{HASIL DAN PEMBAHASAN Hasil dan Analisis Dengan Spektroskopi FT- IR}

Pengujian dengan menggunakan Spektroskopi FT-IR dilakukan pada campuran Karet Alam Siklis (KAS) dan Asam Oleat (AO) sebelum dan setelah dimurnikan. Proses pencangkokkan (grafting) asam oleat pada KAS diperoleh dengan cara melarutkan KAS terlebih dahulu dengan xylena, lalu ditambahkan dengan AO dan diikuti dengan adanya BPO, serta dimurnikan dengan etanol, dikeringkan, dan dianalisis dengan spektroskopi FTIR. Hasil analisis FTIR untuk campuran KAS, AO, dan BPO (70:30:1) phr sebelum pemurnian dan sesudah pemurnian seperti pada Gambar 1. Hasil analisis dengan FTIR pada KAS dan AO dengan inisiator BPO dilakukan sebelum dan sesudah proses pemurnian dengan etanol seperti pada Gambar 1. Berdasarkan hasil spektrum A untuk KAS:AO:BPO sebelum pemurnian diketahui bahwa terdapat serapan tajam dengan intensitas kuat pada $2920,71 \mathrm{~cm}^{-1}$ menunjukkan adanya$\mathrm{CH}$ alifatis streching. Serapan melebar dan lemah pada $2363,18 \mathrm{~cm}^{-1}$ menunjukkan adanya senyawa karbon ikatan rangkap tiga. Serapan pada $1708,23 \mathrm{~cm}^{-1}$ menuunjukkan adanya $\mathrm{C}=\mathrm{O}$ dari asam oleat, adanya serapan tajam dan lemah pada $1586,89 \mathrm{~cm}^{-1}$ menunjukkan adanya ikatan $\mathrm{C}=\mathrm{C}$ dari KAS, yang diperkuat dengan pemunculan $\mathrm{CH}_{2}$ pada $1451,57 \mathrm{~cm}^{-1}$ serta $\mathrm{CH}_{3}$ bending pada $1366,65 \mathrm{~cm}^{-1}$. Adanya ikatan C-O pada asam oleat ditunjukkan dengan adanya serapan melebar dan lemah pada $1203,81 \mathrm{~cm}^{-1}$, adanya serapan melebar dan lemah pada $732,75 \mathrm{~cm}^{-1}$ yang menunjukkan $=\mathrm{CH}$ dari BPO.

Sedangkan pada hasil spektrum B pada Gambar 1 untuk KAS:AO:BPO sesudah pemurnian diketahui bahwa terdapat serapan melebar dengan intensitas lemah pada 3365,95 $\mathrm{cm}^{-1}$ yang menunjukkan adanya gugus $\mathrm{COOH}$ dari asam oleat, sementara pada spektrum A tidak terlihat adanya serapan melebar dengan intensitas lemah pada $3360,05 \mathrm{~cm}^{-1}$ yang disebabkan masih banyaknya zat sisa yang tidak terbentuk pada kopolimer KAS-g-AO. Serapan tajam dengan intensitas kuat pada $2920,81 \mathrm{~cm}^{-1}$ menunjukkan adanya- $\mathrm{CH}$ alifatis streching. Serapan tajam dan sedang pada $2363,18 \mathrm{~cm}^{-1}$ menunjukkan adanya karbon ikatan rangkap tiga $(\mathrm{C}=\mathrm{C})$ yang jelas terbentuk dalam proses grafting setelah pemurnian. Serapan pada 1712,21 $\mathrm{cm}^{-1}$ menuunjukkan adanya $\mathrm{C}=\mathrm{O}$ dari asam oleat, adanya serapan tajam dan sedang pada 1589,18 $\mathrm{cm}^{-1}$ menunjukkan adanya ikatan $\mathrm{C}=\mathrm{C}$ yang meningkat setelah terjadi reaksi antara KAS dan asam oleat, yang diperkuat dengan pemunculan $\mathrm{CH}_{2}$ pada $1442,24 \mathrm{~cm}^{-1}$ dengan serapan yang tajam dan intensitas kuat, serta $\mathrm{CH}_{3}$ bending pada $1361,09 \mathrm{~cm}^{-1}$. Adanya ikatan C-O pada asam oleat ditunjukkan dengan adanya serapan melebar dan lemah pada $1219,70 \mathrm{~cm}^{-1}$, adanya serapan melebar dan lemah pada $732,75 \mathrm{~cm}^{-1}$ yang menunjukkan $=\mathrm{CH}$ dari BPO. Pada kedua spektrum A dan B (Gambar 1) menunjukkan bahwa terdapat asam oleat dalam campuran KAS, dimana asam oleat tercangkok pada KAS setelah adanya inisiator BPO, sehingga terbentuk KASg-AO. 


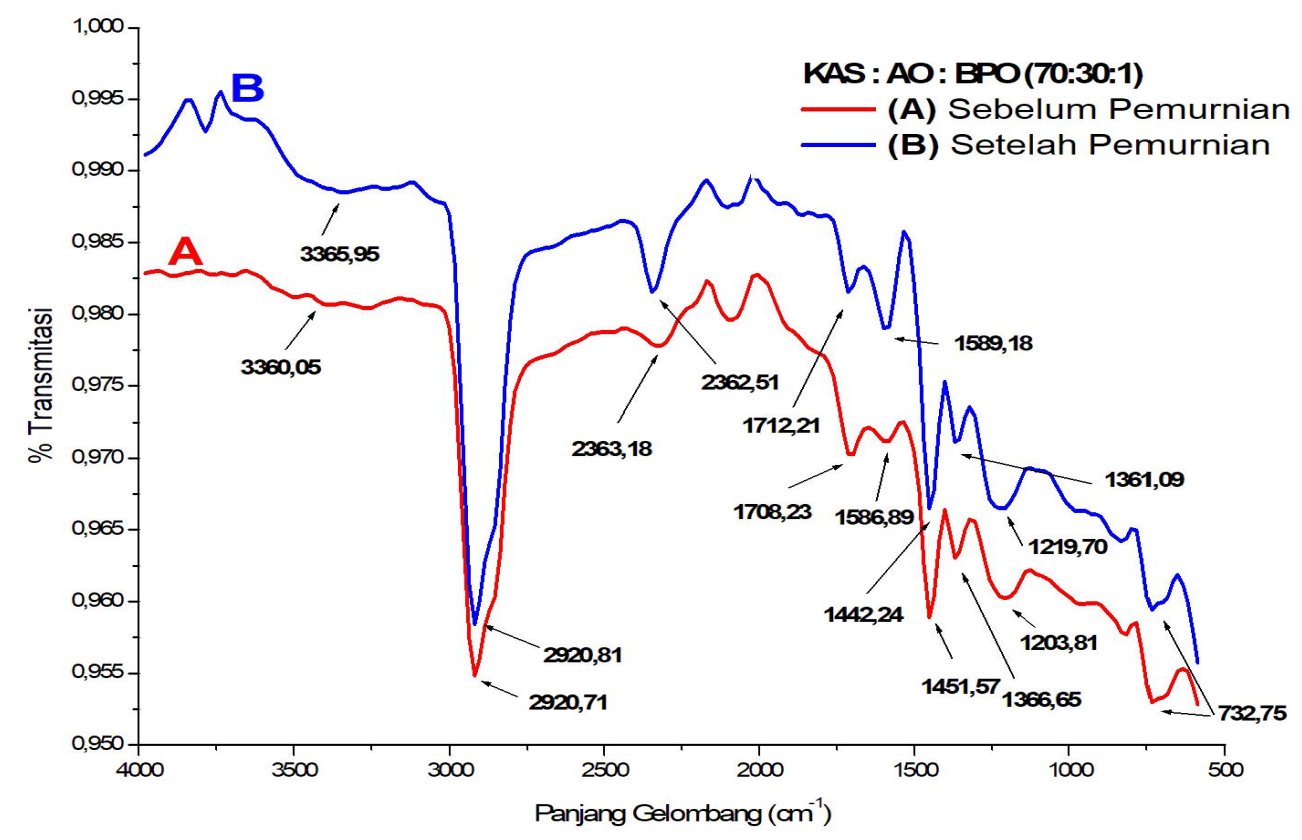

Gambar 1. Spektrum FT-IR KAS, KAS-g-AO dengan inisiator BPO sebelum dan sesudah pemurnian

Pengujian dengan menggunakan Spektroskopi FT-IR dilakukan pada : (1) Karet Alam Siklis (KAS) dan BPO (100:1) phr, (2) campuran KAS, AO, dan inisiator BPO setelah pemurnian, (3) campuran $\mathrm{KAS}, \mathrm{AO}$, inisiator BPO, dan Bentonit-CTAB (70:30:1:3) phr, Proses pencampuran KAS, AO, inisator BPO, dan bahan pengisi Bentonit-Cetil Trimetril Amonium Bromida (CTAB) diperoleh sesuai dengan prosedur modifikasi KAS-gAO/Bentonit-CTAB Dengan Inisiator BPO. Untuk hasil analisis FTIR untuk ketiga campuran tersebut seperti pada Gambar 2.

Berdasarkan hasil spektrum (1) pada Gambar 2 untuk KAS dan BPO diketahui bahwa terdapat serapan tajam dengan intensitas kuat pada $2917,03 \mathrm{~cm}^{-1}$ menunjukkan adanya- $\mathrm{CH}$ alifatis streching. Serapan melebar dan lemah pada $2098,72 \mathrm{~cm}^{-1}$ menunjukkan adanya senyawa karbon ikatan rangkap tiga yang terbentuk terjadinya radikalisasi oleh adanya inisiator BPO. Adanya serapan tajam dan kuat pada $1446,13 \mathrm{~cm}^{-}$ 1 menunjukkan adanya $\mathrm{CH}_{2}$ serta $\mathrm{CH}_{3}$ bending pada $1367,61 \mathrm{~cm}^{-1}$. Adanya serapan melebar dan lemah yang menunjukkan adanya ikatan $\mathrm{C}-\mathrm{O}$ yang terbentuk akibat adanya inisiator BPO dalam KAS, diperkuat dengan adanya serapan melebar dan lemah pada $737,11 \mathrm{~cm}^{-1}$ yang menunjukkan $=\mathrm{CH}$ dari BPO.

Hasil analisis spektrum FTIR (2) pada Gambar 2 untuk KAS dan AO dengan inisiator BPO diketahui bahwa terdapat serapan tajam dengan intensitas kuat pada 2920,71 cm-1 menunjukkan adanya- $\mathrm{CH}$ alifatis streching. Serapan melebar dan lemah pada 2098,40 $\mathrm{cm}^{-1}$ menunjukkan adanya senyawa karbon ikatan rangkap tiga. Serapan pada $1708,23 \mathrm{~cm}^{-1}$ menuunjukkan adanya $\mathrm{C}=\mathrm{O}$ dari asam oleat, adanya serapan tajam dan lemah pada 1586,89 $\mathrm{cm}^{-1}$ menunjukkan adanya ikatan $\mathrm{C}=\mathrm{C}$ dari KAS, yang diperkuat dengan pemunculan $\mathrm{CH}_{2}$ pada $1446,13 \mathrm{~cm}^{-1}$ serta $\mathrm{CH}_{3}$ bending pada 1367,65 $\mathrm{cm}^{-1}$. Adanya ikatan C-O pada asam oleat ditunjukkan dengan adanya serapan melebar dan lemah pada 1255,66 $\mathrm{cm}^{-1}$, adanya serapan melebar dan lemah pada $732,75 \mathrm{~cm}^{-1}$ yang menunjukkan $=\mathrm{CH}$ dari $\mathrm{BPO}[13-15]$. 


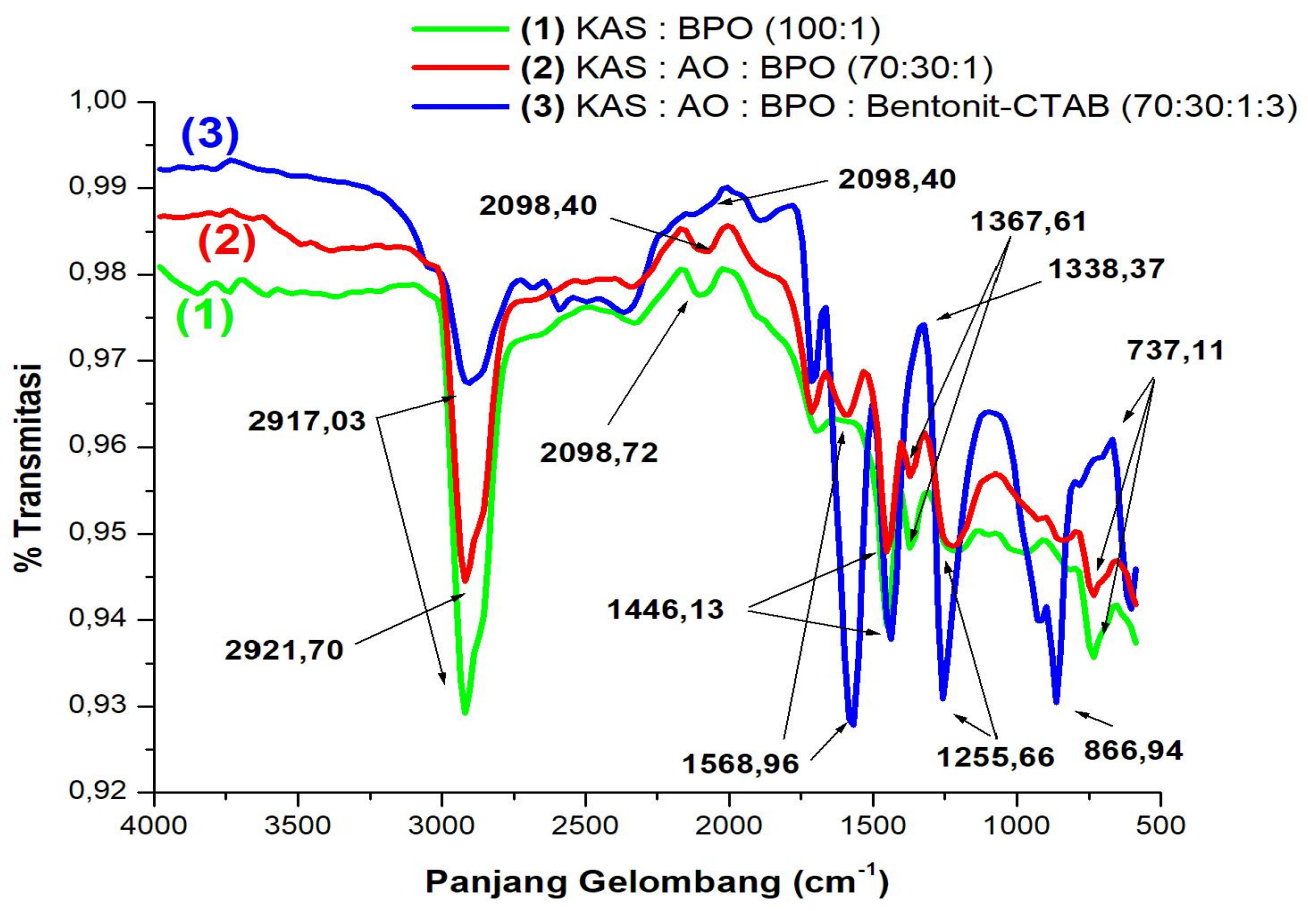

Gambar 2. Spektrum FT-IR : (1) KAS; (2) KAS, AO, dan iisiator BPO; (3) KAS, AO, BPO, dan BentonitCTAB.

Sementara itu, hasil analisis spektrum FTIR (3) pada Gambar 2 untuk KAS, AO, inisiator BPO, dan bahan pengisi Bentonit-CTAB diketahui bahwa terdapat serapan tajam dengan intensitas kuat pada $2917,03 \mathrm{~cm}^{-1}$ menunjukkan adanya-CH alifatis streching. Tidak munculnya serapan pada $2098,40 \mathrm{~cm}^{-1}$ menunjukkan bahwa telah terjadinya pemutusan ikatan rangkap setelah adanya BPO serta berikatan dengan bentonitCTAB yang ditambahkan bersamaan setelah inisiator BPO. adanya senyawa karbon ikatan rangkap tiga. Serapan pada $1708,23 \mathrm{~cm}^{-1}$ menuunjukkan adanya $\mathrm{C}=\mathrm{O}$ dari asam oleat, adanya serapan tajam dan lemah pada 1568,96 $\mathrm{cm}^{-1}$ menunjukkan adanya ikatan $\mathrm{C}=\mathrm{C}$ dari KAS, yang diperkuat dengan pemunculan $\mathrm{CH}_{2}$ pada $1446,13 \mathrm{~cm}^{-1}$ dengan serapan yang tajam dengan intensitas yang kuat, akan tetapi tidak diiringi dengan pemunculan serapan pada $1367,65 \mathrm{~cm}^{-1}$, yang berarti tidak ada $\mathrm{CH}_{3}$. Adanya ikatan $\mathrm{C}-\mathrm{O}$ pada asam oleat ditunjukkan dengan adanya serapan tajam dan kuat pada 1255,66 $\mathrm{cm}^{-1}$, adanya pemunculan serapan tajam dan kuat pada $866,94 \mathrm{~cm}^{-1}$ dan serapan melebar dan lemah $732,75 \mathrm{~cm}^{-1}$ yang menunjukkan $=\mathrm{CH}$ dari bentonit-CTAB dan BPO [16, 17].

Pada ketiga spektrum (1), (2), dan (3) dari Gambar 2 menunjukkan bahwa terdapat asam oleat telah tercangkok pada KAS setelah penambahan BPO, dimana munculnya serapan pada $1708,23 \mathrm{~cm}^{-1}$ menuunjukkan adanya $\mathrm{C}=\mathrm{O}$ dari asam oleat, dan $1586,89 \mathrm{~cm}^{-1}$ menunjukkan adanya ikatan $\mathrm{C}=\mathrm{C}$. Sedangkan adanya bahan pengisi bentonit-CTAB menyebabkan serapan semakin menguat dan tajam pada $1568,96 \mathrm{~cm}^{-1}$, $1446,13 \mathrm{~cm}^{-1}, 1255,66 \mathrm{~cm}^{-1}$, dan $866,94 \mathrm{~cm}^{-1}$.

\section{Hasil dan Analisis Pengujian Dengan SEM}

Pengujian menggunakan scanning electron microscope (SEM) dilakukan pada material KAS-g-AO/Bentonit-CTAB untuk mengetahui struktur permukaan karet alam siklis yang dihasilkan setelah dilakukan pencampuran dengan asam oleat, dan bentonit-CTAB.. Struktur permukaan tersebut dapat menjadi suatu gambaran umum mengenai kualitas pencampuran antara KAS, AO dan BPO, serta persebaran dari pengisi bentonit-CTAB. Bagian yang dilihat meliputi permukaan bagian atas. Perbedaan perbesaran untuk melihat lebih jelas perbedaan dalam pencampuran $[12,18]$.

Pada Gambar 3a untuk perbesaran 250 kali, terlihat partikel-partikel berukuran kecil yang tersebar pada seluruh permukaan material. Partikel-partikel ini merupakan Bentonit-CTAB yang terperangkap atau terikat pada KAS-g-AO oleh adanya inisiator BPO dengan ukuran partikel tidak teratur. Hal ini terlihat lebih jelas pada perbesaran 500 kali (Gambar 3b) dan juga pada perbesaran 1000 kali (Gambar 3c) dimana 
ada Bentonit-CTAB-nya yang berukuran besar dan juga kecil, yang disebabkan dalam sebelum

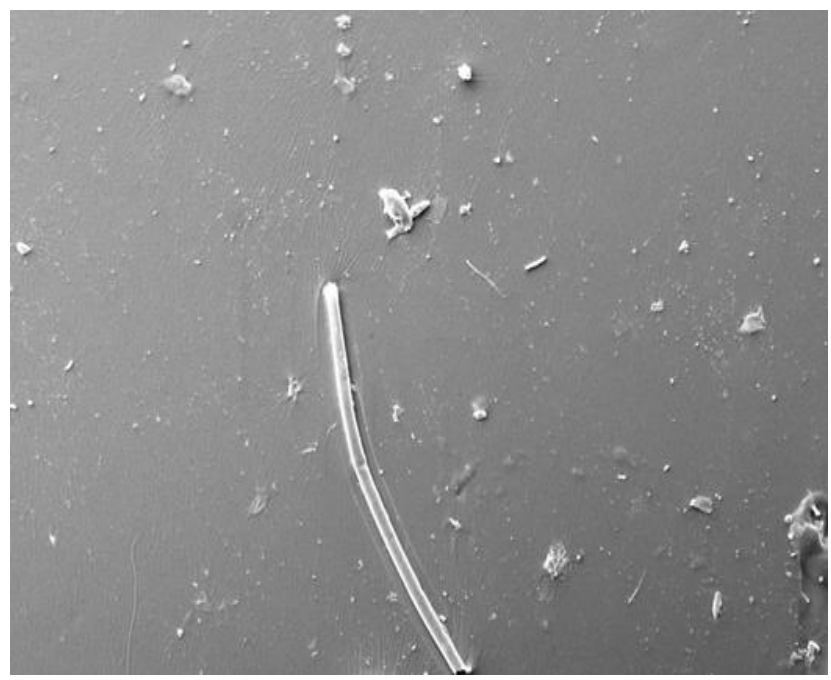

(a) proses pencampuran bentonit-CTAB tidak dihaluskan terlebih dahulu.

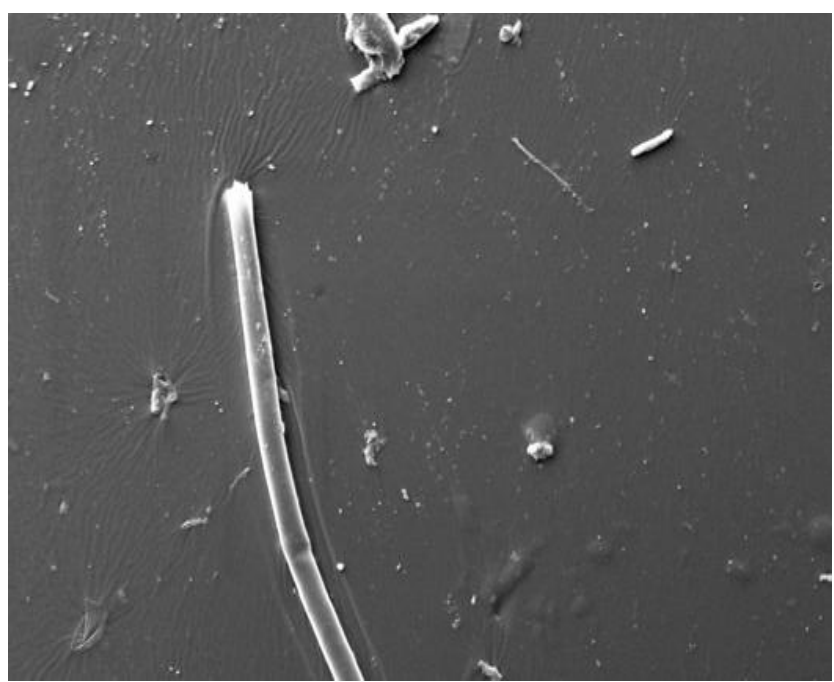

(b)

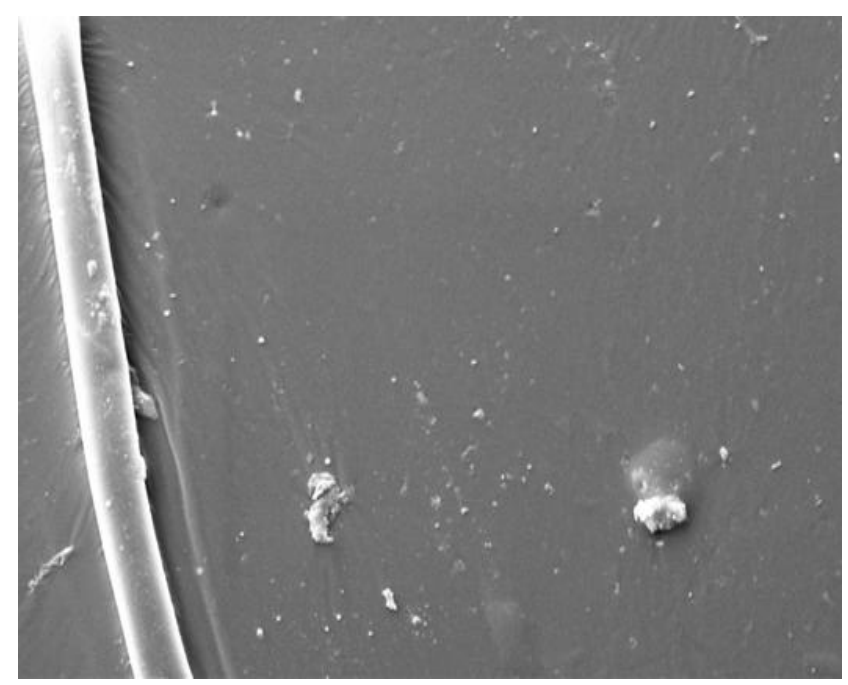

(c)

Gambar 3. Hasil SEM Campuran KAS-g-AO/Bentonit CTAB (a) Perbesaran 250 kali; (b) Perbesaran 500 kali; dan (c) Perbesaran 1000 kali

Adanya penyebaran merata Bentonit-CTAB dalam KAS-g-AO menunjukkan bahwa campuran tersebut homogen. Sedangkan munculnya garis panjang pada Gambar 3 (a), (b), dan (c) yang menyerupai pipa hal tersebut merupakan kotoran yang ikut tercampur pada saat proses pencampuran dilakukan.

\section{KESIMPULAN}

Dari hasil penelitian dapat disimpulkan bahwa Karet Alam Siklis (KAS) dan Asam Oleat (AO) dapat dimodifikasi dengan penambahan inisiator Benzoil Peroksida (BPO) dan bahan pengisi Bentonit-CTAB dengan komposisi perbandingan untuk KAS : AO : BPO : BentonitCTAB sebanyak (70:30:1:3) phr, dengan suhu pemanasan $50 \quad{ }^{\circ} \mathrm{C}$ selama 1 jam, sehingga diperoleh kopolimer KAS-g-AO/Bentonit-CTAB yang dianalisis dengan spektroskopi FTIR terlihat adanya serapan pada $1708,23 \mathrm{~cm}^{-1}$ yang mengindikasikan adanya ikatan $\mathrm{C}=\mathrm{O}$ dari asam oleat yang telah tercangkok pada KAS, serta peningkatan intensitas setelah adanya penambahan bentonit-CTAB pada $1568,96 \mathrm{~cm}^{-1}$, $1446,13 \mathrm{~cm}^{-1}, 1255,66 \mathrm{~cm}^{-1}$, dan $866,94 \mathrm{~cm}^{-1}$, serta ditinjau dengan SEM terlihat adanya 
pencampuran Bentonit-CTAB dalam KAS-g-AO tersebut tersebar secara merata dan homogen.

\section{DAFTAR PUSTAKA}

[1] Mirzataheri, M. (2000). The Cyclization Of Natural Rubber. Iranian Journal of Chemistry and Chemical Engineering (IJCCE), 19(2), 91-96. Iranian Institute of Research and Development in Chemical Industries (IRDCI)-ACECR.

[2] Siregar, M. S., Tamrin, \& Basuki, W. S. (2015). Modifikasi Karet Alam Siklis (Cyclic Natural Rubber/CNR) Dengan Teknik Grafting: Menggunakan Monomer Metil Metakrlat Dan Inisiator Benzoil Peroksida. Agrium: Jurnal Ilmu Pertanian, 17(3).

[3] Siregar, M. S. (2012). Modifikasi Dan Karakterisasi Karet Alam Siklis (Resiprena 35) Dengan Anhidrida Maleat Sebagai Substituen Bahan Pengikat Cat Sintetis. Disertasi-USU.Medan.

[4] Eddiyanto, Ardina, Y. W., \& Siregar, M. S. (2015). Modifikasi Proses Pembuatan Karet Alam Siklis (Cyclic Natural Rubber) Melalui Reaksi Pemutusan Rantai (Chain Scission) Dan Siklisasi. Agrium: Jurnal Ilmu Pertanian, 18(1).

[5] Siregar, M. S., \& Syaputra, I. R. (2015). Grafting Maleat Anhidrat Pada Karet Alam Siklis (Cyclic Natural Rubber/CNR) Dengan Inisiator Dicumyl Peroksida. Agrium: Jurnal Ilmu Pertanian, 17(2).

[6] Rzayev, Z. M. O. (2011). Graft Copolymers Of Maleic Anhydride And Its Isostructural Analogues: High Performance Engineering Materials. arXiv preprint arXiv:1105.1260.

[7] Stöckelhuber, K. W., Das, A., Jurk, R., \& Heinrich, G. (2010). Contribution Of Physico-Chemical Properties Of Interfaces On Dispersibility, Adhesion And Flocculation Of Filler Particles In Rubber. Polymer, 51(9), 1954-1963. Elsevier.

[8] Sari, A., \& Ibýldak, Ö. (2006). Adsorption Properties Of Stearic Acid Onto Untreated Kaolinite. Bulletin of the Chemical Society of Ethiopia, 20(2). Chemical Society of Ethiopia.

[9] Mihajlović, S., Sekulić, Ž., Daković, A., Vučinić, D., Jovanović, V., \& Stojanović, J. (2009). Surface Properties Of Natural Calcite Filler Treated With Stearic Acid. Ceram. Silik, 53(4), 268-275.
[10] Sarı, A., Tuzen, M., \& Soylak, M. (2007). Adsorption Of $\mathrm{Pb}$ (II) And Cr (III) From Aqueous Solution On Celtek Clay. Journal of Hazardous Materials, 144(1-2), 41-46. Elsevier.

[11] Boyd, S. A., Sheng, G., Teppen, B. J., \& Johnston, C. T. (2001). Mechanisms For The Adsorption Of Substituted Nitrobenzenes By Smectite Clays. Environmental science \& technology, 35(21), 4227-4234. ACS Publications.

[12] Pan, H., Lan, Y., Wu, R., Chen, P., He, G., $\& \quad \mathrm{Wu}, \mathrm{H}$. (2008). Interfacial Characterization Of Organic Bentonite With Cetyl Trimethyl Ammonium Bromide And Sodium Dodecyl Sulfate. Journal of South China Normal University (Natural Science Edition), 1, 17.

[13] Ritonga, A. H., Aritonang, B., \& Anggeraini, R. (2018). Pemanfaatan Cetil Trimetil Amonium Bromida Sebagai Filler Dalam Pembuatan Komposit Karet Alam Siklis Grafting Maleat Anhidrat/Organobentonit. Jurnal Kimia Saintek dan Pendidikan, 2(1), 41-49.

[14] Ritonga, A. H. (2017). Modifikasi Aspal Polimer Memanfaatkan Karet Ban Bekas Menggunakan Divenil Benzena Dan Dikumil Peroksida Melalui Proses Ekstrusi. Jurnal Kimia Saintek Dan Pendidikan, 1(1), 8-13.

[15] Ritonga, A. H. (2017). Karakterisasi Aspal Polimer Dari Limbah Polistirena Dan Serbuk Karet Ban Bekas Menggunakan Divenil Benzena Dan Inisiator Dikumil Peroksida. Akademia, 21(2), 7-14.

[16] Ritonga, A. H. (2017). Pembuatan Aspal Polimer Menggunakan Karet SIR-20 Yang Diinisiasi Oleh Adanya Dikumil Peroksida Melalui Proses Ekstrusi. Jurnal Stikna, 1(2), 123-130.

[17] Ritonga, A. H. (2017). Modifikasi Aspal Polimer Memanfaatkan Karet Ban Bekas Menggunakan Divenil Benzena Dan Dikumil Peroksida Melalui Proses Ekstrusi. Jurnal Kimia Saintek dan Pendidikan, I(2009), 8-13.

[18] Endriani, D., \& Ritonga, A. H. (2006). The Influence Of Addition Palm Shell Ash To Mineralogy And Physical Properties Of Clay Soil. 